\title{
Correlation between Urban Morphology and Wind Environment in Digital City using GIS and CFD Simulations
}

\author{
http://dx.doi.org/10.3991/ijoe.v10i3.3631 \\ Jie Yin, Qingming Zhan, Yinghui Xiao, Tao Wang, Erzhuo Che, Fanshuo Meng, Yi Qian \\ Wuhan University, Wuhan, China
}

\begin{abstract}
Digital city technology has been used increasingly in planning and architectural design, and it has become a powerful means for solving problems faced in a city. In China, more than $61 \%$ of the population will live in cities by 2020 ; this proportion will increase to $69 \%$ by 2030 . The city's internal environment is deteriorating. Using information technology, this study focuses on both the urban and the residential neighbourhood scale to explore the relationship between the urban morphology and the urban wind environment. At the urban scale, using geographic information system (GIS)-based spatial analysis and calculating the frontal area density (FAD) and roughness length, the building density and building volume density (BVD) can help improve the urban wind environment. At the residential neighbourhood scale, through computational fluid dynamics (CFD) simulations, the building density has a strongly linear relationship with the average pedestrian wind speed; however, the floor area ratio, average building height, and average wind speed show weak correlation.
\end{abstract}

Index Terms-Digital city, Geographic information systems (GIS), Computational fluid dynamics (CFD), Frontal area density (FAD)

\section{INTRODUCTION}

According to the United Nations Economic and Social Council, more than half of the world's population lived in cities in 2012. In China, one of the most rapidly urbanising countries, more than $61 \%$ of the population is expected to live in cities by 2020 . This proportion may increase to $69 \%$ by 2030 . Usually, cities are developed by improving the infrastructure and building density to cope with the dual pressure of population growth and scarce land resources. However, inhabitants of high-density cities face harmful problems such as summer heat, automobile exhaust pollution, and industrial pollution, including hazy weather. To achieve sustainable development in such cities, the quality of the internal environment should be improved and energy consumption should be reduced for the efficient use of natural resources.

The pedestrian wind environment is an important factor affecting the quality of the environment within the city. It strongly impacts the thermal comfort and wind. Furthermore, it disperses and therefore weakens traffic exhaust and thermal pollution. Therefore, studies on the pedestrian wind environment have great significance for urban planning.
The wind entering the city is affected by the surface roughness, and its flows and patterns vary. Oke (1988) focused on the environmental characteristics of wind in an urban canyon. Based on height to width ratios $(\mathrm{H}: \mathrm{W})$, the flow characteristics of the wind environment have been divided into three modes: isolated roughness flow, Wake interference flow, and Skimming flow [1]. Other factors such as the arrangement, density, and height and width of a building may also affect the near-surface wind speed. Ng (2009) studied high-density buildings [2]. Hong Kong's wind environment has been improved through planning and architectural design strategies. The ventilation has been improved through some methods such as the establishment of ventilation channels, street toward, open spaces, water space layouts, nonconstruction areas, building height, podium building scale, building permeability, building orientation, and green areas. Nowadays, most studies aim to simplify the urban roughness using regular aligned buildings through computational fluid dynamics (CFD) numerical simulations and wind tunnel tests. However, few studies use real urban areas. With regard to simple structured buildings, researchers need to determine important and unimportant morphological parameters for simplifying the urban form. However, they cannot effectively represent the complex layout of urban spaces. For example, Adolphe (2011) assimilated the urban form as a porous medium using a spatial model consisting of a series of environmental parameters such as density, rugosity, porosity, sinuosity, occlusivity, compacity, contiguity, solar admittance, and mineralisation [3].

In urban planning and architectural design, improving the building density in urban areas is often assumed to reduce wind speed. In addition, most studies have shown that it is difficult to explain the relation between the reduction in average wind speed with people's height and the increased building density. This study aims to explain this difficult problem using a digital city. A quantitative study is conducted using of geographic information system (GIS) analysis and CFD. However, this study does not consider the land form and building layout, although both greatly impact the pedestrian wind environment.

\section{WIND ENVIRONMENT IN STUdy AREA AND DATA SOURCES}

During the year, Fuzhou's predominant wind direction is northeast and south. The typhoon period is from July to September; yearly, on average, two typhoons land directly in cities. Although Fuzhou's wind direction is 
significantly affected by the terrain, atmospheric circulation dominates during the year to a considerable extent. At the beginning of September, Fuzhou is hit by cold air. In winter, the wind direction is north and northwest. From February to August, more southerly wind appears. Fuzhou is a coastal city. In the summer, the southwest monsoon prevails. Furthermore, low pressure appears over the land area, and land and sea breezes are strong. Obviously, our body can feel the sea breeze from the southeast to the northwest, especially during the daytime when it blows from the sea to the dry land. Therefore, in the summer, Fuzhou is affected by both the monsoon and the sea breezes between day and night. Obviously, the sea breeze changes, and owing to the prolonged effect of the monsoon in the city, inhabitants feel the sea breeze to be stronger in the monsoon. Therefore, during the summer, the dominant wind direction is in the southeast.

Based on statistics from the World Meteorological Organization, the Fuzhou Strait Olympic simulation will use three dominant wind directions: southeast, $30^{\circ}$ northeast, and $20^{\circ}$ southwest (Fig. 1). In the southeast, the maximum, minimum, and average wind speed is calculated to be $11.11,1.38$, and $4.69 \mathrm{~m} / \mathrm{s}$, respectively. The southeast wind shows greater variation owing to the rapidly changing summer sea breeze during day and night. However, the land temperature drops at night; as a result, the pressure gradient decreases, resulting in the sea breeze blowing slowly and a weak breeze gradually emerging. During the day, the land temperature rises, and the air density decreases. Furthermore, the increase in pressure differs between the sea and the land. Overall, the sea breeze remains dominant, and therefore, inhabitants can feel the sea breeze from the southeast. Table 1 shows the specific distribution of the summer wind speed. In addition, other data sources such as building data of status quo and planning were obtained from the census data of Cangshan District, Fuzhou.

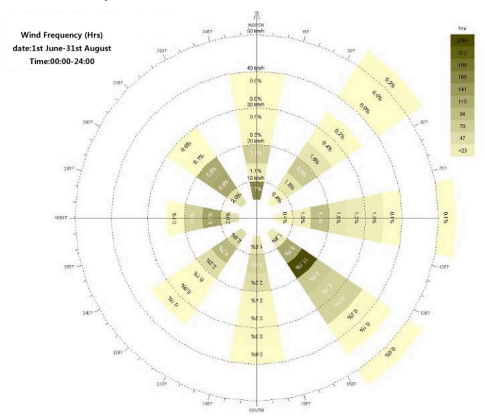

Figure 1. Frequency of summer wind in Fuzhou

TABLE I.

DISTRIBUTION OF SUMMER WIND SPEED (M/S)

\begin{tabular}{|c|c|c|c|}
\hline $\mathbf{m} / \mathbf{s}$ & Southeast & Northeast & Northwest \\
\hline $\begin{array}{c}\text { maximum } \\
\text { value }\end{array}$ & 11.11 & 8.89 & 3.01 \\
\hline $\begin{array}{c}\text { minimum } \\
\text { value }\end{array}$ & 1.38 & 1.46 & 0.28 \\
\hline $\begin{array}{c}\text { average } \\
\text { value }\end{array}$ & 4.69 & 2.67 & 1.46 \\
\hline
\end{tabular}

III. STUDY METHODS

GIS and CFD are mainly used as the study methods. At an urban scale, we determine the correlation between the ground coverage ratio (GCR) and building volume density (BVD) and the urban air ventilation potential by calculating the frontal area density (FAD) of a built-up environment and the roughness length $\left(z_{0}\right)$ using GIS. At a street scale, we determine the correlation between the building density and the urban air ventilation potential by calculating the average wind speed using CFD.

\section{A. Geographic Information Systems}

The GCR, building volume (BV), BVD, FAD, and roughness length $\left(z_{0}\right)$ are all calculated using a geographical information platform.

The roughness length $\left(z_{0}\right)$ is calculated as follows: (1) Integrate a $1-\mathrm{m}$ building height grid into a $100-\mathrm{m}$ grid by using the Aggregate tool, select 'MEAN' in the Aggregate technique, and denote the obtained 100-m grid of average building height by [Mean Height]. (2) Calculate the roughness length using the following formula [4]. (Note: Owing to the relation between the roughness length and the $\mathrm{FAD}$, the former is also related to the wind direction.)

$$
z_{0}=[\text { MeanHeight }]^{*}[F A D]^{*} 0.5
$$

\section{B. Turbulence Model}

Wind in the atmospheric boundary layer possesses the characteristics of turbulence, and the wind gradient and scales of the turbulence are determined by the near-ground surface roughness. The standard $k-\varepsilon$ model affords advantages such as low computational cost, small fluctuations, and high accuracy in the numerical calculations, and therefore, we use it in this study. The wind environment is simulated using the 'PHOENICS' software. The standard $k-\varepsilon$ model provides two equations for turbulent kinetic energy $k$ and dissipation rate $\varepsilon$ to simulate the wind speed and turbulence length, respectively, and the control equation is given as follows [5]:

$$
\begin{aligned}
& v_{t}=\frac{c_{\mu} k^{2}}{\varepsilon} \\
& \frac{\partial k}{\partial t}+U_{i} \frac{\partial k}{\partial x_{i}}=\frac{\partial}{\partial x_{i}}\left(\frac{v_{t}}{\delta_{k}} \frac{\partial k}{\partial x_{i}}\right) \\
& +v_{t}\left(\frac{\partial U_{i}}{\partial x_{j}}+\frac{\partial U_{j}}{\partial x_{i}}\right) \frac{\partial U_{i}}{\partial x_{j}}-\varepsilon \\
& \frac{\partial \varepsilon}{\partial t}+U_{i} \frac{\partial \varepsilon}{\partial x_{i}}=\frac{\partial}{\partial x_{i}}\left(\frac{v_{t}}{\delta_{\varepsilon}} \frac{\partial \varepsilon}{\partial x_{i}}\right) \\
& +\frac{C_{1 \varepsilon} \varepsilon}{k}\left(\frac{\partial U_{i}}{\partial x_{j}}+\frac{\partial U_{j}}{\partial x_{i}}\right) \frac{\partial U_{i}}{\partial x_{j}}-C_{2 \varepsilon} \frac{\varepsilon^{2}}{k} \\
& C_{1 \varepsilon}=1.44, C_{2 \varepsilon}=1.92, C_{\mu}=0.09, \\
& \delta_{K}=1.0, \delta_{\varepsilon}=1.3
\end{aligned}
$$

where $U_{i}$ is the mean wind velocity in the $x_{i}$ direction ( $i=1,2,3) ; U_{j}$ is the mean wind velocity in the $x_{j}$ direction $(j=1,2,3) ; x, y$, and $z$ are the Cartesian co-ordinates; $v_{t}$ is the eddy (or turbulent) viscosity; and $C_{\mu}, \delta_{k}, \delta_{\varepsilon}, C_{1 \varepsilon}$, and $C_{2 \varepsilon}$ are the constants in the standard $k-\varepsilon$ model. 


\section{Boundary Conditions}

Appropriate boundary conditions need to be fixed before simulating the wind environment of the residential neighbourhood level. Based on a previous analysis of the wind speed and wind direction, the average wind speed with the highest frequency is fixed as the input condition for the simulation area. The wind speed is $4.69 \mathrm{~m} / \mathrm{s}$ and it is selected at $10-\mathrm{m}$ height of the southeast wind. The power law is set as 0.142857 . The wind gradient can be approximated by a power law model as follows [5]:

$$
U(z)=U_{G} \times\left(\frac{z}{z_{G}}\right)^{a}
$$

In this equation, $U(z)$ is the wind speed at height $z$; $U_{G}$, the wind speed at reference height; $z$, the height from the ground; $Z_{G}$, the reference height; and $a$, a constant reflecting the surface roughness.

\section{URBAN SCALE}

At the urban scale, this study uses the theory of surface roughness along with the GIS spatial analysis platform and wind direction. The new cross profile method is adopted to calculate the FAD in order to evaluate the urban surface roughness. Then, an air permeability parameter database at the urban scale is built to describe the urban air permeability. This method can be used to determine the potential ventilation channel. Compared with CFD and the wind tunnel test, it is can be used more easily by planners and architects for design and application.

Existing studies use the wind velocity ratio (VR) to evaluate the wind environment. After natural wind enters the city, the city surface is rougher than the in the suburb, and therefore, the natural wind speed decreases with an increase in height. The wind speed ratio at different heights is determined by the morphological characteristics of the urban roughness and the FAD.

\section{A. Morphological Characteristics of Current Situation and Urban Planning}

The GCR and BVD are important indexes of the layout and urban form. GCR only reflects the plane layout and does not consider the building height. On the other hand, BVD can directly reflect the building height distribution and indirectly reflect the development intensity in the city.

In the Cangshan district of Fuzhou, areas with GCR exceeding $50 \%$ are concentrated in the south, and more than $70 \%$ of these are connected. In addition, there exist some areas with GCR exceeding $50 \%$ in the north. The GCR is high in the southern part of Cangshan district and the eastern part of the third ring expressway (Fig. 4). The abovementioned regions are villages with small and intensive buildings. Such regions have considerable development potential, and they may play a very important role in solving the urban heat island problem. Yesha and Qiaodong districts are considered special because they contain few high-rises but many low-rises; therefore, GCR and BCD are both high. The main parts of some other districts with low-rises have high GCR and low BVD whereas those of some districts with high-rises have moderate GCR and high BVD (Figs. 2, 4).

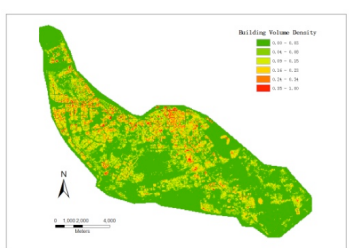

Figure 2. Distribution map of building volume density in Cangshan district, Fuzhou

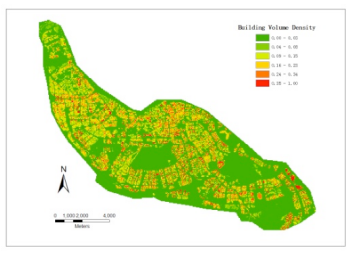

Figure 3. Distribution map of building volume density of proposed planning in Cangshan district, Fuzhou

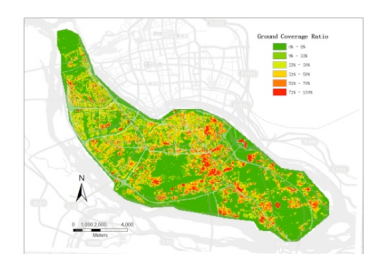

Figure 4. Distribution map of ground coverage ratio in Cangshan district, Fuzhou

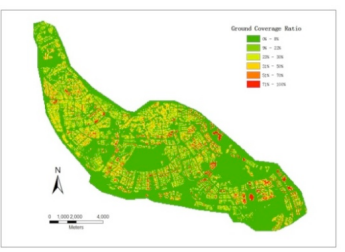

Figure 5. Distribution map of ground coverage ratio of proposed planning in Cangshan district, Fuzhou

In the Cangshan district of Fuzhou, there exists a large difference between the current and planned building layouts. The obvious changes are high-density low-rises along the street. Through urban planning, these houses have been demolished and repaired, thus improving the house layout along the street and reducing the GCR (Fig. 5). At the same time, reformed buildings are typically mid- and high-rises, and therefore, the BVDs of the corresponding districts are increasing (Fig. 3).

\section{B. Analysis of Natural Ventilation Potential}

After natural wind enters the city, it is hampered by the elements of the city, which sharply reduces its velocity in the city. Air flow in buildings has reduced by over $90 \%$ compared to that for open spaces in the suburbs. The city's natural ventilation potential (NVP) refers to the ventilation ability of the artificial urban environment. In fact, the ventilation potential can be used to study the relationship between the elements of the city and the wind.

Oke (1979) proposed the concept of urban canopy layer (UCL) as a research area. The UCL could be investigated independently unlike in traditional studies of the urban wind field. He claimed that the UCL and urban boundary layer should be distinguished while studying 
either urban ventilation or urban heat island considering the distinctive meteorology properties between the two [6]. Therefore, the UCL, defined as the space between the urban ground surface and the mean height of urban constructions and which is strongly related to human activities, became the primary area in the urban wind field. Studies could cover the microscale of a single building within the UCL to the macroscale of the entire canopy layer.

The FAD of the buildings is calculated as follows [7]:

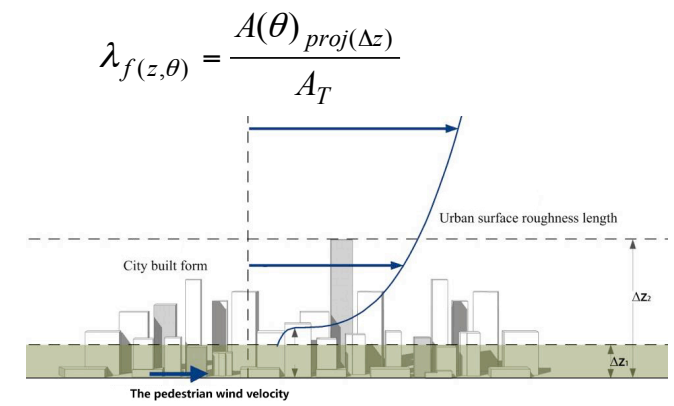

Figure 6. Urban morphology within UCL; wind profile and projection of FAD at a certain height. (Near surface height $\Delta z_{1}$, maximum architectural height $\Delta z_{2}$ )

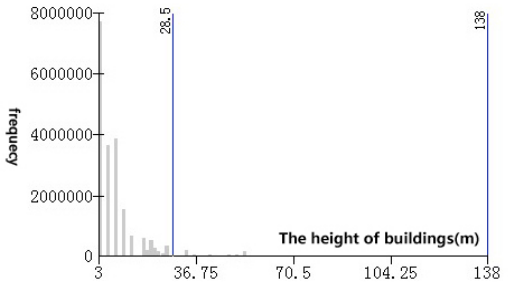

Figure 7. Distribution of architecture height value of Cangshan district: the maximum height is $138 \mathrm{~m}$, whereas the natural breakpoints for the current and planned urban structures are $28.5 \mathrm{~m}$.

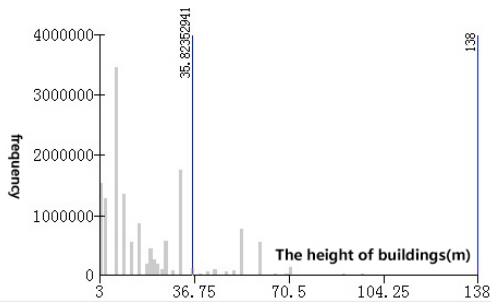

Figure 8. Distribution of architecture height value of Cangshan district: the maximum height is $138 \mathrm{~m}$, whereas the natural breakpoints for the current and planned urban structures are $35.8 \mathrm{~m}$.

where $A(\theta)_{\operatorname{proj}(\Delta z)}$ is the projection of the FAD in the wind direction; $A_{T}$, the size $\left(100 \times 100 \mathrm{~m}^{2}\right)$ of the grid involved in the calculation; and $\Delta z$ the area of the projection at a certain height. Figure 6 shows the situation in which wind passes through the urban surface within the UCL. The blue line indicates the profile of the average wind speed; the wind speed decreases proportionately with the height. However, the near surface wind speed could not be indicated by the average wind speed line and could only be derived according to local architectural geometric properties. Previous studies have shown that wind permeation largely depends on the near surface architectural shapes and urban cluster morphology.
Therefore, this study focuses on the FAD at the near surface height $\Delta z_{1}$, which should be a proper estimator of wind permeation at pedestrian height.

The near-surface height could be obtained through a statistical method by studying the distribution of the architecture height (Figs. 7 and 8). According to the natural breakpoint indicated in the graph, the height of the near-surface FAD projection area could be defined as 0-30 m either for the current or he planned urban structure $\left(\Delta z_{1}=30 \mathrm{~m}\right)$. The same height is set to conduct a proper cross-sectional comparison such that the development of ventilation potential can be determined.

The wind direction is denoted by $\theta$. In this study, up to 6 directions are defined to calculate the FAD. The ventilation potential obtained for these directions would be the basic estimator in this study. If the wind frequencies are equal in each direction, the average FAD can be obtained as follows:

$$
\lambda_{f\left(z_{i}\right)}=\sum_{\theta=1}^{3} \lambda_{f\left(z_{i} \theta\right)} * P_{\theta}
$$

where $P_{\theta}$ is the wind frequency in a certain direction ( $P_{1}=P_{2}=P_{3}=\frac{1}{3}$ ), and $i$ denotes the height of a certain projection area.

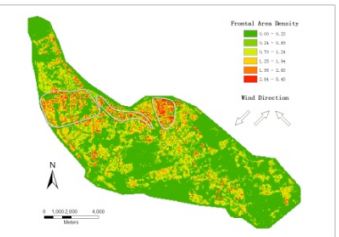

Figure 9. Assembled FAD of Cangshan district, Fuzhou for primary summer wind direction

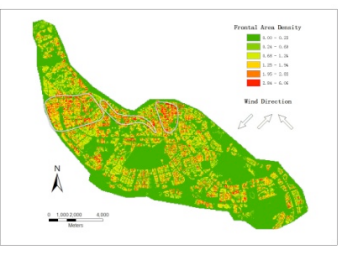

Figure 10. Corresponding FAD of planned urban structure

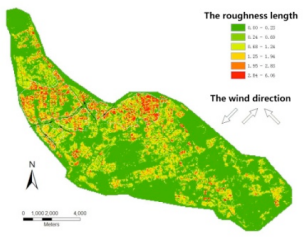

Figure 11. Surface roughness of Cangshan district, Fuzhou for primary summer wind direction

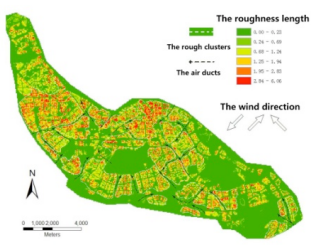

Figure 12. Corresponding roughness of planned urban structure. 
The FADs are calculated and analysed in 3 primary directions-summer primary monsoon (northeast and southwest) and land-sea breeze (southeast) - and they are assembled by adding them up to obtain the integrative result (Figs. 9 and 10) [4,7,8]. The roughness distribution is found to be relatively low (Fig. 11); in fact, the entire Cangshan district can be considered a smooth area. A few regions with relatively high roughness value are scattered to the west and north; these areas have relatively low GCR and high BVD, reflecting the fact that areas with high FAD generally contain high-rises with larger spaces among themselves and that building height is the primary factor impacting the urban ventilation potential. Therefore, it is necessary to improve the ventilation environment through wind ducts such as major roads, open spaces, green corridors, rivers, and lakes. In urban planning and construction, existing ducts should be retained and building layouts should be optimised during planning to construct new ducts for better ventilation in a region.

The architecture distribution after planning is strongly optimised for improved urban ventilation potential. The building density or GCR is controlled suitably. High-rises constitute the majority of constructions, leading to increased development intensity or BVD. After planning, the roughness and FAD of Cangshan district increased in most places (Figs. 10 and 12), despite which the ventilation potential remained the same or even improved owing to the removal and reorganisation of old buildings, suitable arrangement of new constructions, preservation of existing ventilation paths and addition of new ones, and design in areas with higher roughness.

\section{RESIDENTIAL NEIGHBOURHOOD SCALE}

\section{A. Study Cases}

Eight cases are considered for the planning of Cangshan district, Fuzhou (Figs. 13 and14). The gross building area, gross floor area, GCR, BVD, and average height and floor are presented for each case. Kubota considered a wind tunnel test with a unit size of $270 \mathrm{~m} \times$ $270 \mathrm{~m}$ and total land area of $72900 \mathrm{~m}^{2}$ [11]; this study uses the same unit size.

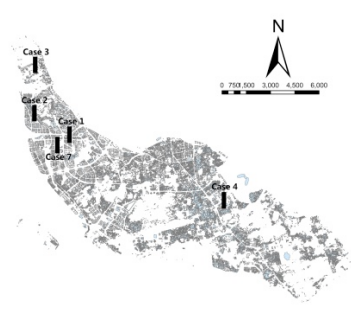

Figure 13. Map of status quo in Cangshan District, Fuzhou

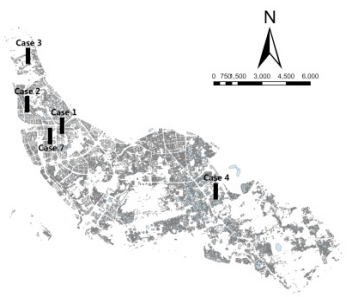

TABLE II.

BRIEF OUTLINE OF CASE STUDY AREAS FOR CFD

\begin{tabular}{|c|c|c|c|c|c|c|}
\hline \multirow[t]{2}{*}{ Case } & \multirow{2}{*}{$\begin{array}{c}G C R \\
(\%)\end{array}$} & \multirow{2}{*}{$\begin{array}{c}B V D \\
(\%)\end{array}$} & \multicolumn{4}{|c|}{ Proportion of building floor (\%) } \\
\hline & & & $\begin{array}{c}1-2 \\
\text { floors }\end{array}$ & $\begin{array}{c}3-5 \\
\text { floors }\end{array}$ & $\begin{array}{c}\text { 6-14 } \\
\text { floors }\end{array}$ & $\begin{array}{c}>14 \\
\text { floors }\end{array}$ \\
\hline Case 1 & 27.1 & 160 & 22.0 & - & 78.0 & - \\
\hline Case 2 & 43.5 & 139 & 26.1 & 69.6 & 4.3 & - \\
\hline Case 3 & 34.5 & 137.2 & 40.0 & 36.0 & 24.0 & - \\
\hline Case 4 & 63.4 & 195 & 24.7 & 60.3 & 15.0 & - \\
\hline Case 5 & 17.4 & 191 & - & - & 100 & - \\
\hline Case 6 & 19.7 & 66.3 & 23.1 & 76.9 & - & - \\
\hline Case 7 & 24 & 166 & 9.4 & - & 90.6 & - \\
\hline Case 8 & 33.7 & 219.9 & - & 46.2 & 38.5 & 15.3 \\
\hline
\end{tabular}

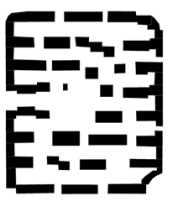

Figure 15. Building layout of Case 1

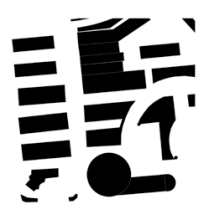

Figure 16. Building layout of Case 2

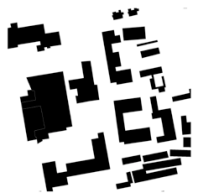

Figure 17. Building layout of Case 3

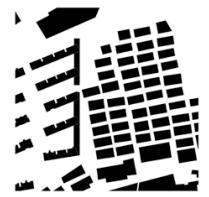

Figure 18. Building layout of Case 4

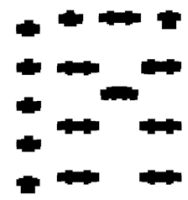

Figure 19. Building layout of Case 5

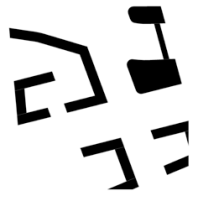

Figure 20. Building layout of Case 6 


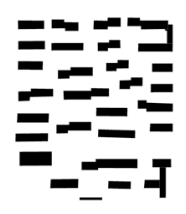

Figure 21. Building layout of Case 7

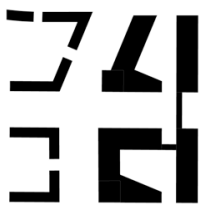

Figure 22. Building layout of Case 8

\section{B. Simulated Result}

Figure 23 shows the relationship between the GCR and the average pedestrian wind speed. The latter decreases with an increase in the building density. However, it shows weak relations with other urban morphology factors such as the development intensity and average building height. This study found that the average pedestrian wind may increase with the development intensity and average building height. It follows that a block's building density is closely related to the pedestrian-level wind environment. Reducing a block's building density and using reasonable layouts will help improve the ventilation potential of lands.

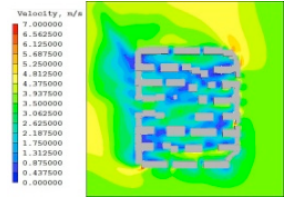

Figure 23. Distribution map of wind speed in Cases 1

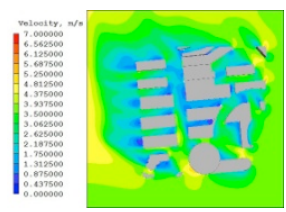

Figure 24. Distribution map of wind speed in Cases 2

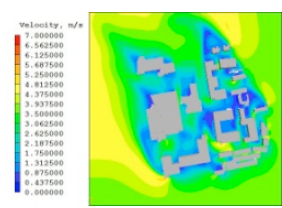

Figure 25. Distribution map of wind speed in Cases 3

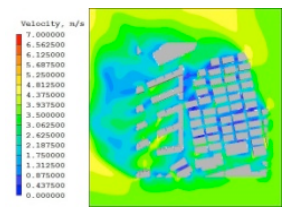

Figure 26. Distribution map of wind speed in Cases 4

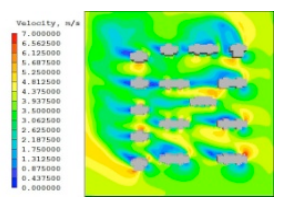

Figure 27. Distribution map of wind speed in Cases 5

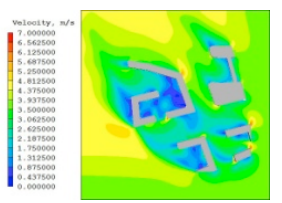

Figure 28. Distribution map of wind speed in Cases 6

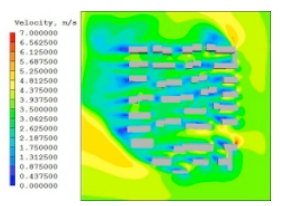

Figure 29. Distribution map of wind speed in Cases 7

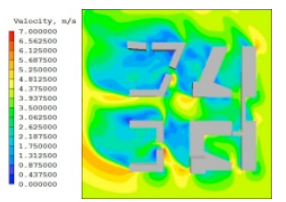

Figure 30. Distribution map of wind speed in Cases 8

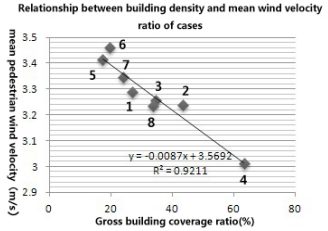

Figure 31. Relationship between building density and average pedestrian wind velocity

\section{CONCLUSIONS}

A quantitative analysis of the urban morphology and ventilation potential of the Cangshan district, Fuzhou yielded the following results: (1) At an urban scale, good ventilation can be achieved by changing the building density and BVD. This study compares the status quo and the planning at the urban scale and shows that better ventilation is achievable by retaining existing and adding new ventilation corridors while reducing building density and a reasonable increasing the floor area ratio (FAR). (2) The strong correlation between the average wind speed at $1.5-\mathrm{m}$ height and the building density suggests that a city's ventilation potential can be improved by increasing the building interval and setback and setting up open spaces in urban construction. Unlike the building density, the average building height and development intensity show weak correlations with the average pedestrian height wind. Furthermore, this study showed that building layout model is both strongly related to the urban ventilation potential. A city's ventilation potential can be improved assuming that a parallel duct with a dominant wind direction exists or the frontal area density is small. All of these relationships will be quantified in future studies. 


\section{REFERENCES}

[1] T. R. OKE. "Street Design and Urban Canopy Layer Climate". Energy and Buildings, Vol 11, Issues 3, March 1988, pp.103 113 .

[2] Edward Ng. "Policies and technical guidelines for urban planning of high-density cities - air ventilation assessment (AVA) of Hong Kong”. Building and Environment, Vol 44, Issue 07, July 2009, pp.1478-1488. http://dx.doi.org/10.1016/j.buildenv.2008.06.013

[3] Luc Adolphe. "A simplified model of urban morphology: application to an analysis of the environmental performance of cities". Environment and planning B : Planning \& Design, Vol 28, Issue 2, 2001, pp.183-200. http://dx.doi.org/10.1068/b2631

[4] Lettau,H.."Note on aerodynamic roughness-parameter estimation on the basis of roughness-element description". Journal of applied meteorology, Vol 8, Issue 05, October 1969, pp.828-832. http://dx.doi.org/10.1175/1520-0450(1969)008<0828:NOARPE $>$ 2.0.CO;2

[5] Cheng-Hu Hu., Fan Wang. "Using a CFD approach for the study of street-level winds in a built-up area". Building and Environment, Vol 40, Issue 05, May 2005, pp.617-631, .

[6] T.R. Oke. "The distinction between canopy and boundary - layer urban heat islands". Atmosphere. Vol 14, Issue 04, March1976, pp.268-277,

[7] Ng, E., C. Yuan, L. Chen, C. Ren, J. Fung. "Improving the wind environment in high-density cities by understanding urban morphology and surface roughness: a study in Hong Kong". Landscape and Urban planning, Vol 101, Issue 01, May 2011, pp.59-74. http://dx.doi.org/10.1016/j.landurbplan.2011.01.004

[8] Grimmond, C. S. B. and T. R. Oke. "Aerodynamic properties of urban areas derived from analysis of surface form”. Journal of applied meteorology, Vol 38, Issue 09, September 1999, pp.1262-1292,http://dx.doi.org/10.1175/1520-0450(1999)038<12 62:APOUAD $>2.0 . \mathrm{CO} ; 2$

[9] Chao Yuan, Edward Ng. "Building porosity for better urban ventilation in high-density cities e A computational parametric study". Building and Environment, Vol 50, Issue 04, April 2012, pp.176-189,. http://dx.doi.org/10.1016/j.buildenv.2011.10.023

[10] Feng Yang, Feng Qian, Stephen S.Y. Lau. "Urban form and density as indicators for summertime outdoor ventilation potential: A case study on high-rise housing in Shanghai". Building and Environment, Vol 70, Issue 12, December 2013, pp.122-137,. http://dx.doi.org/10.1016/j.buildenv.2013.08.019

[11] Tetsu Kubotaa, Masao Miurab, Yoshihide Tominagac, Akashi Mochidad. "Wind tunnel tests on the relationship between building density and pedestrian-level wind velocity: Development of guidelines for realizing acceptable wind environment in residential neighbourhoods". Building and Environment, Vol 43, Issue 10, October 2008, pp.1699-1708, http://dx.doi.org/10.1016/ j.buildenv.2007.10.015

\section{AUTHORS}

Jie Yin Author is with School of Urban Design, Wuhan University, Wuhan 430072, China. He is now with Research Center for Digital City, Wuhan University, Wuhan 430072, China (e-mail: 64673543@qq.com).

Qingming Zhan Author is with School of Urban Design, Wuhan University, Wuhan 430072, China. He is now with Research Center for Digital City, Wuhan University, Wuhan 430072, China (e-mail: qmzhan@ whu.edu.cn).

Yinghui Xiao Author is with School of Urban Design, Wuhan University, Wuhan 430072, China. He is now with Research Center for Digital City, Wuhan University, Wuhan 430072, China (e-mail: yhxiao1963@qq.com).

Tao Wang Author is with School of Urban Design, Wuhan University, Wuhan 430072, China. He is now with Research Center for Digital City, Wuhan University, Wuhan 430072, China (e-mail: 519457522@qq.com).

Erzhuo Che Author is with School of Remote Sensing and Information Engineering, Wuhan University, Wuhan 430072, China. He is now with Research Center for Digital City, Wuhan University, Wuhan 430072, China (e-mail: 24448937@qq.com).

Fanshuo Meng Author is with School of Remote Sensing and Information Engineering, Wuhan University, Wuhan 430072, China. He is now with Research Center for Digital City, Wuhan University, Wuhan 430072, China (e-mail: fsmeng@whu.edu.cn).

Yi Qian Author is with School of Urban Design, Wuhan University, Wuhan 430072, China (e-mail: 104279183@qq.com).

This work was supported by the National Natural Science Foundation of China (Project No.: 51378399). Submitted, March, 8, 2014. Published as resubmitted by the authors on May, 16, 2014. 